\title{
Rancang Bangun Perangkat Lunak Monitoring Menggunakan Sensor Timbangan Dinamis Terhadap Muatan Kendaraan Dan Penindakan Pada Gerbang Tol
}

\author{
Yuni Arkhiansyah ${ }^{1}$, Muhammad Hidayat ${ }^{2}$ \\ ${ }^{1,2}$ Institut Informatika dan Bisnis Darmajaya \\ 1yuniarki@darmajaya.ac.id, 22dayatt.1711010174@mail.darmajaya.ac.id
}

\begin{abstract}
ABSTRAK
Perkembangan teknologi informasi dan komunikasi di era sekarang ini begitu cepat, kebutuhan untuk melakukan aktivitas dan komunikasi secara realtime sangat dibutuhkan didalam beberapa bidang industri seperti misalnya di Gerbang Tol. Dan salah satu medianya adalah alat sensor, adapun alat sensor yang dimaksud adalah timbangan kendaraan dinamis (sensor) yang mampu mendeteksi beban keseluruhan kendaraan tanpa menimbulkan antrian yang panjang digerbang tol. Metode pengembangan perangkat lunak yang digunakan dalam sistem ini adalah metode Prototype. Dimana tahapan Protoype terdiri dari Mendengarkan Pelanggan, Membangun dan Memperbaiki Prototype serta Uji Coba. Metode prototype digunakan untuk menggali kebutuhan secara lebih tepat dan melibatkan pengguna secara langsung yang dalam hal ini ditemukan beberapa masalah. Hasil Penelitian ini dijelaskan mengenai Hasil dan Implementasi progam dari berbagai tahapan yang telah dirancang sebelumnya. Perlu diperhatikan sebelum Admin mulai menjalankan perangkat lunak untuk melakukan monitoring, pastikan perangkat (personal computer) memiliki sistem operasi Windows 10 Pro, dan terknoneksi dengan jaringan, dan juga perangkat lunak Backend telah di konfigurasi oleh seorang Teknisi. Setelah poin-poin yang disebutkan sudah tidak ada masalah, maka Admin dapat menjalankan perangkat lunak monitoring tersebut.
\end{abstract}

Kata kunci: Weigh in Motion Scale Sensors, Desktop Application, Perangkat Lunak Monitoring, Prototype, Windows 10.

\section{PENDAHULUAN}

Perkembangan teknologi informasi dan komunikasi di era sekarang ini begitu cepat, kebutuhan untuk melakukan aktivitas dan komunikasi secara realtime sangat dibutuhkan didalam beberapa bidang industri seperti misalnya di Gerbang Tol. Dan salah satu medianya adalah alat sensor, adapun alat sensor yang dimaksud adalah timbangan kendaraan dinamis (sensor) yang mampu mendeteksi beban keseluruhan kendaraan tanpa menimbulkan antrian yang panjang digerbang tol. Penelitian ini akan menggunakan antarmuka desktop (desktop application) sebagai tampilan yang dapat dilihat oleh user/pengguna dan sistem pendukung yang bergerak dibelakang layar sebagai basis penelitian yang mendukung kinerja penggunaan alat sensor, yang dimana dari kedua perangkat lunak yang akan dibangun berjalan di sistem operasi Windows 10. Dalam membangun perangkat lunak yang akan dibuat penulis menggunakan Microsoft Visual Studio sebagai IDE yang digunakan untuk membangun perangkat lunak.

IDE yang digunakan dalam membangun perangkat lunak adalah Microsoft Visual Studio, karena perangkat lunak yang akan digunakan akan berjalan di sistem operasi Windows 10. Dan lebih mudah jika ingin melakukan integrasi dengan perangkat lunak lainnya yang berbasis Windows. Sehingga penulis memilih Microsoft Visual Studio ini untuk dapat menyelaraskan perangkat lunak yang akan dibangun untuk Gerbang Tol Trans Sumatera, dengan yang sudah ada agar dapat saling terintegrasi dengan baik. 
Jalan Tol Trans Sumatera Bakauheni - Terbanggi Besar sepanjang 141 KM yang dikelola PT. Hutama Karya (Persero) dibangun pada tahun 2019. Terhitung sejak mulai dioperasikannya hingga akhir tahun 2020 telah terjadi kasus kecelakaan lalulintas.

Faktor penyebab kecelakaan disebabkan oleh human error dan juga kendaraan dengan beban muatan yang melebihi batas sehingga menyebabkan kerusakan ruas jalan. Sehingga terjadi kasus kecelakaan pada kendaraan tersebut dan juga kendaraan lain yang melintas, dan juga membuat umur jalan yang seharusnya mencapai angka efektif selama sepuluh tahun, ini menjadi berkurang. Untuk membatasi kendaraan dengan beban muatan berlebih yang mengunakan jalan tol diperlukan suatu alat yang dapat mengidentifikasi beban kendaraan yang melintas sehingga membantu pengelola jalan tol untuk dilakukan penindakan terhadap kendaraan yang melebihi batas beban muatan (Overload).

Dari uraian diatas masih terdapat beberapa kekurangan dari alat timbangan dinamis yang digunakan, salah satunya kurang beberapa item guna untuk melakukan monitoring dan juga memberikan data beban kendaraan untuk dilakukan penindakan apakah kendaraan tersebut Overload atau tidak, maka dari itu diperlukan adanya tambahan perangkat lunak pendukung untuk melakukan monitoring data kendaraan secara realtime untuk melengkapi kekurangan dari alat timbangan yang digunakan.

\section{LANDASAN TEORI}

\subsection{Perangkat Lunak}

Perangkat Lunak/software merupakan sekumpulan perintah/fungsi yang ditulis dengan aturan tertentu untuk memerintahkan komputer agar melaksanakan sesuatu, (Ladjamudin, 2005).

\subsection{Aplikasi}

Aplikasi merupakan sekelompok atribut yang terdiri dari beberapa form, report yang disusun sedemikian rupa sehingga dapat mengakses data. Aplikasi merupakan program yang berisi perintah untuk melakukan olah data, secara umum aplikasi adalah suatu proses dari cara manual yang dipindahkan ke dalam komputer dengan membuat sistem atau program agar data diolah lebih berdaya guna secara optimal, (Rahman dan Santoso, 2015).

\subsection{Desktop Application}

Aplikasi desktop adalah aplikasi yang berdiri sendiri yang diinstal pada komputer desktop atau laptop. Ini bisa berfitur lengkap seperti Microsoft Excel atau melakukan satu atau dua fungsi seperti aplikasi kalender. Biasanya, aplikasi desktop dibatasi oleh perangkat keras yang dijalankannya. Dikombinasikan dengan aplikasi terminal mainframe, mereka memiliki antarmuka pengguna yang tidak kompleks. Mereka juga sulit untuk diperbarui, terutama jika peningkatan perangkat keras diperlukan agar aplikasi berfungsi. (Arif Fahrudin, 2020).

Aplikasi berbasis desktop merupakan aplikasi yang dijalankan pada masing-masing komputer atau klien. Aplikasi berbasis desktop harus diinstall terlebih dahulu ke dalam komputer agar dapat digunakan. Berdasarkan pengertian diatas penulis menyimpulkan bahwa aplikasi desktop adalah aplikasi yang berjalan pada komputer yang dapat digunakan secara langsung ketika kode program selesai dikompilasi. (Rafyrp101, 2013).

\subsection{Basis Data (Database)}

Basis Data (Database) adalah tempat penyimpanan data dan informasi secara terstruktur dan teratur, yang digunakan sebagai pangkalan data atau tempat berkumpulnya data secara digital. Pada database terdapat sebuah 
sistem yang disebut DBMS (Database Management System), DBMS adalah sebuah sistem untuk membantu aplikasi dan pengguna di dalam melakukan manajemen data dan database. Beberapa contoh DBMS yang umum digunakan di dunia komputer, antara lain adalah MySQL, Postgre SQL, Oracle, Microsoft SQL Server, Maria DB, Mongo DB, dan lainnya, (I Putu Agus Eka Pratama, 2018).

\subsection{Pengertian Bahasa C\#}

C\# (C sharp) adalah" sebuah bahasa pemrograman berbasis obyek yang didukung oleh Microsoft .NET Framework". Microsoft .NET Framework adalah perantara agar aplikasi dengan bahasa pemrograman yang didukung dapat berkomunikasi dengan sistem operasi yang digunakan oleh komputer kebanyakan orang. Selain itu, .NET Framework juga memungkinkan $C \#$ untuk berkomunikasi dengan bahasa pemrograman lainnya yang juga didukung oleh .NET Framework seperti VB .NET, F\#, atau C++", (Handoyo, 2011).

\subsection{API (Application Programming Interface)}

Application Programming Interface (API) adalah alat yang membuat data situs web dapat dicerna untuk komputer. Karakteristik yang membuat situs web optimal bagi manusia, namun membuat sulit digunakan oleh komputer sehingga dibutuhkanlah sebuah API. Melalui API, komputer dapat melihat dan mengedit data, sama seperti seseorang yang dapat memuat halaman dan submit formulir. Apa yang mungkin membutuhkan waktu berjam-jam dengan manusia untuk menyelesaikannya, namun dapat memakan waktu beberapa detik dengan komputer melalui API. Ketika dua sistem terhubung melalui API, dapat dikatakan bahwa dua sistem tersebut terintegrasi. Satu sisi yaitu server dan sisi lain yaitu klien. Dalam sisi server sebenarnya yang menyediakan API. Jika dalam sisi klien, dapat mengetahui data apa yang tersedia melalui API dan dapat memanipulasinya, biasanya atas permintaan dari pengguna. Request method nantinya akan memberitahu server tindakan apa yang diinginkan pengguna untuk diambil oleh server, (Girish M. Rama, Avinash Kak, 2015).

Terdapat empat method yang sering digunakan pada API, yaitu:
a. $\quad$ GET : Meminta server untuk mengambil suatu data.
b. POST : Meminta server untuk menambah suatu data.
c. $\quad P U T$ : Meminta server untuk memperbaharui suatu data.
d. DELETE : Meminta server untuk menghapus suatu data.

\subsection{Pengujian Kotak Hitam (Black Box Testing)}

Pengujian Black-Box Testing (Kotak Hitam), juga disebut dengan Pengujian Prilaku. Berfokus pada persyaratan fungsional perangkat lunak. Artinya, teknik pengujian Black-Box Testing memungkinkan untuk membbuat beberapa kumpulan kondisi masukan yang sepenuhnya akan melakukan semua kebutuhan fungsional untuk program. Pengujian Black-Box Testing merupakan pendekatan pelengkap yang mungkin dilakukan untuk mengungkap kelas kesalahan yang berbeda dari yang diungkap metode lainnya, (Roger S. Pressman, 2012).

Black Box Testing mencoba untuk menemukan kesalahan dalam kategori berikut:
1. $\quad$ Uji Interface.
2. Uji Fungsi Menu dan Tombol.
3. Uji Struktur dan Database. 


\subsection{Metode Prototype}

Prototype digunakan untuk menggali kebutuhan secara lebih cepat. Biasanya saat pembuatan ptototype, keterlibatan user sangat dibutuhkan. Manfaat utama prototype adalah untuk mengurangi resiko tidak diterimanya hasil pengembangan suatu perangkat lunak serta pengulangan kerja di kemudian hari, (Munawar, 2018).

\subsection{Unified Modelling Language (UML)}

UML (Unified Modelling Language) adalah salah satu alat bantu yang sagat handal di dunia pengembangan system yang berorientasi objek. Hal ini disebabkan karena UML menyediakan bahasa pemodelan visual yang memungkinkan bagi pengembang sistem untuk membuat cetak biru atas visi mereka dalam bentuk yang baku, mudah dimengerti. UML merupakan kesatuan dari bahasa pemodelan yang dikembangkan oleh Booch, Object Medeling Technique (OMT) dan Object Oriented Software Engineering (OOSE). Metode ini menjadikan proses analisis dan desain ke dalam empat tahapan interatif, yaitu : identifikasi kelas-kelas dan objek-objek, identifikasi semantic dari hubungan objek dan kelas tesebut, perincian interface dan implementasi. UML dibangun atas model 4+1 view. Yaitu LogicalView, Development View, Process View, Physical View dan Scenario. Model ini di dasarkan pada fakta bahwa struktur sebuah system dideskripsikan dalam 5 View, yang salah satunya adalah Scenario, (Munawar, 2018).

\subsubsection{Use Case Diagram}

Use Case Diagram adalah deskripsi fungsi sebuah system dari perspektif pengguna. Use Case Diagram bekerja dengan cara mendeskripsikan tipikal interaksi antara pengguna sebuah system dengan sistemnya sendiri melalui sebuah cerita bagaimana sebuah system dipakai. Urutan langkah-langkah yang menerangkan antara pengguna dan system disebut sebagai scenario. Setiap scenario menggambarkan urutan kejadian. Setiap urutan di inisialisasi oleh orang, system yang lain, perangkat keras atau urutan waktu. Dengan demikian, secara singkat bias dikatakan Use Case Diagram adalah serangkaian scenario yang digabungkan bersaa-sama oleh tujuan umum pengguna. Use Case dibuat berdasarkan kebutuhan Aktor. Use Case Diagram harus merupakan "apa" yang dikerjakan software aplikasi, bukan "bagaimana" software aplikasi mengerjakannya, (Munawar, 2018).

Tabel 1 pada halaman berikut ini adalah Simbol-simbol yang digunakan dalam Use Case Diagram:

Tabel 1. Use Case Diagram

\begin{tabular}{|c|c|}
\hline Simbol & Keterangan \\
\hline Nama Use Case & $\begin{array}{l}\text { Fungsionalitas yang disediakan system sebagai unit yang saling bertukar pesan antara } \\
\text { unit atau factor, biasanya dinyatakan dengan menggunakan kata kerja awal frase nama } \\
\text { Use Case }\end{array}$ \\
\hline Aktor & $\begin{array}{l}\text { Orang, proses atau sistem lain yang berinteraksi dengan system yang akan dibuat di } \\
\text { luar system yang akan dibuat itu sendiri. Jadi, walaupun symbol dari aktor adalah } \\
\text { gambar orang, tapi aktor belum tentu orang. Biasanya dinyatakan menggunakan kata } \\
\text { benda di awal frase nama aktor. }\end{array}$ \\
\hline Asosiasi & Komunikasi antara aktor dan Use Case, atau Use Case dan Aktor \\
\hline$\underset{\longrightarrow}{\longrightarrow}$ & $\begin{array}{l}\text { Hubungan Generalisasi dan Spesialisasi (Umum - Khusus) antara dua buah Use Case } \\
\text { dimana fungsi yang satu adalah fungsi yang lebih umum dari lainnya. }\end{array}$ \\
\hline Ekstensi / Extend & $\begin{array}{l}\text { Relasi Use Case tambahan ke sebuah Use Case dimana Use Case yang ditambahkan } \\
\text { dapat berdiri sendiri walaupun tanpa Use Case tambahan. }\end{array}$ \\
\hline (r............... & \\
\hline
\end{tabular}




\section{Include}

Relasi Use Case tambahan ke sebuah Use Case, dimana Use Case yang ditambahkan memerlukan Use Case ini untuk menjalankan fungsinya atau sebagai syarat dijalankan Use Case ini.

\subsubsection{Activity Diagram}

Munawar (2018: 127) mengurakan bahwa Activity Diagram adalah bagian penting dari UML yang menggambarkan aspek dinamis dari Sistem. Logika Prosedural, proses bisnis dan aliran kerja suatu bisnis bisa dengan mudah di deskripsikan dalam Activity Diagram. Activity Diagram mempunyai peran seperti halnya Flowchart, akan tetapi perbedaannya dengan Flowchart adalah Activity Diagram bisa mendukung perilaku paralel sedangkan Flowcharti tidak bisa.

Tabel 2. Use Case Diagram

\begin{tabular}{ll}
\hline Simbol & \multicolumn{1}{c}{ Keterangan } \\
aktifitas.
\end{tabular}

\section{METODOLOGI}

\subsection{Metode Pengembangan Perangkat Lunak}

Pada tahapan membangun perangkat lunak, penelitian ini dilakukan dengan menggunakan metode yang telah dipilih, yaitu Metode Prototype. Dikarenakan dalam konteks ini sebelum melanjutkan ke tahap perilisan perangkat lunak yang sudah siap digunakan secara penuh, diperlukan adanya suatu testing perangkat lunak terlebih dahulu guna peninjauan sebelum masuk ke tahap akhir. Proses ini juga dilakukan secara intensif untuk menspesifikasi kebutuhan perangkat lunak agar dapat memenuhi keinginan User (Pengguna).

\subsubsection{Komunikasi}

Dalam tahapan komunikasi dari model metode prototype guna untuk mengidentifikasi permasalahanpermasalahan yang ada, dan juga informasi-informasi lain yang akan diperlukan dalam membangun perangkat lunak. 
Pengumpulan data yang digunakan dalam menyusun serta melengkapi data adalah dengan cara observasi, wawancara dan studi pustaka, antaranya:

a. Observasi

Pengamatan langsung untuk memperoleh data yang dilakukan pada tempat penelitian yang terkait dengan penelitian dilakukan pada lajur yang terdapat timbangan dinamis dijalan tol milik PT. Hutama Karya (Persero).

b. Wawancara

Wawancara dilakukan dengan cara berkomunikasi langsung dengan pihak yang bertanggung jawab dibagian timbangan dinamis ini baik dari pihak pengelola tol maupun dari pihak penyedia timbangan dinamis.

\section{c. Studi Pustaka}

Studi pustaka dilakukan untuk memperoleh data dan informasi dengan membaca berbagai bahan penulisan, karya ilmiah serta sumber-sumber lain mengenai permasalahan yang berhubungan dengan penulisan.

\subsubsection{Perencanaan Secara Tepat}

Tahapan ini dikerjakan dengan kegiatan penentuan sumber daya, spesifikasi untuk membangun berdasarkan kebutuhan sistem, dan tujuan berdasarkan pada hasil komunikasi yang dilakukan agar pembangunan perangkat sesuai dengan yang diharapkan pengguna.

\subsubsection{Permodelan Perancangan Secara Tepat}

Tahapan selanjutnya ialah representasi atau menggambarkan model sistem yang akan dikembangkan seperti proses dengan perancangan menggunakan Unified Modeling Language (UML) yang menerapkan Use Case Diagram, Activity Diagram, dan Class Diagram. Dalam tahap ini, Prototype yang dibangun dengan sistem rancangan sementara kemudian dievaluasi terhadap klien apakah sudah sesuai dengan yang diinginkan atau masih perlu dilakukan untuk di evaluasi kembali. Setelah perangkat lunak dianggap sesuai dengan apa yang diharapkan klien, langkah berikutnya yaitu masuk ke tahap pembuatan perangkat lunak / perangkat lunak dari rancangan sistem yang dibuat diterjemahkan ke dalam bahasa pemrograman $C \#$ yang diintegrasikan dengan pengguna basis data $M y S Q L$.

\section{a. Use Case Diagram}

Use Case Diagram digunakan untuk pemodelan kegiatan pada sistem yang akan dibuat. Gambar 1 berikut ini adalah rancangan Use Case Diagram yang akan dibuat: 


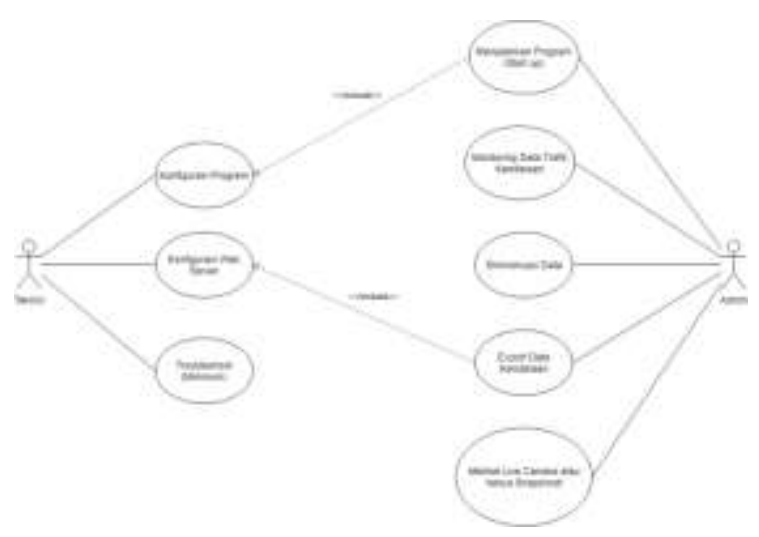

Gambar 1. Use Case Diagram Monitoring Software

Berdasarkan Use Case Diagram pada gambar 1 dapat dijelaskan fungsi masing-masing dari User Use Case sebagai berikut:

1. Teknisi melakukan konfigurasi awal perangkat lunak.

2. Teknisi menyiapkan sebuah web server untuk digunakan di perangkat lunak.

3. Teknisi melihat log yang di tulis oleh perangkat lunak, dan digunakan untuk melakukan troubleshooting.

4. Admin yang menjalankan perangkat lunak

5. Admin dapat melihat data kendaraan yang melintas di perangkat lunak monitoring.

6. Proses ketika terjadi ketidak sinkronan perangkat lunak monitoring yang disinkronisasi manual oleh Admin.

7. Admin dapat melakukan export data kendaraan yang telah melintasi lajur timbangan.

8. Admin melihat proses media dari kamera yang ingin ditampilkan di perangkat lunak monitoring.

b. Activity Diagram

Digunakan untuk menggambarkan alur dari awal sebuah sistem, melakukan, dan mengakhiri proses. Activity Diagram yang akan diterapkan pada sistem ini adalah sebagai berikut:

\section{Activity Diagram Teknisi}

Activity Diagram Teknisi merupakan urutan langkah-langkah yang dilakukan Teknisi dalam melakukan tugasnya. Mulai dari melakukan konfigurasi perangkat lunak, konfigurasi Web Server, dan Troubleshooting. Activity Diagram Teknisi. Gambar 2 pada halaman berikut adalah Activity Diagram Teknisi dari perangkat lunak Monitoring yang akan dibuat:

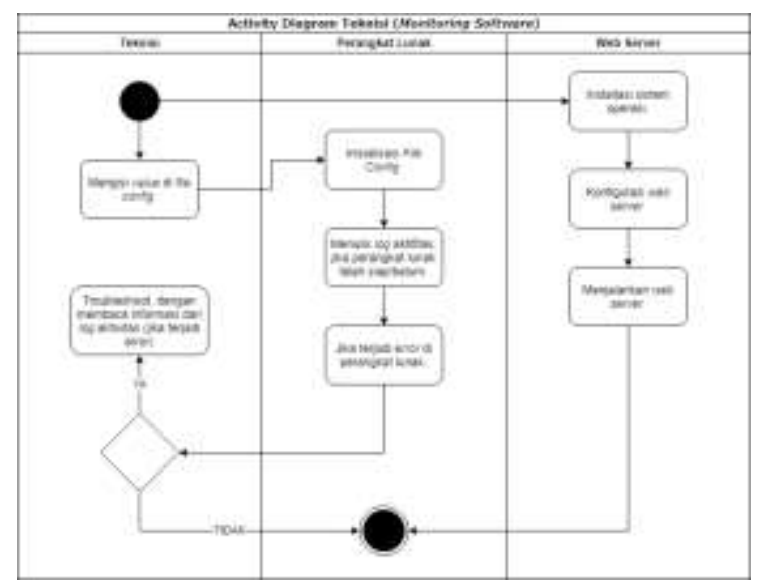

Gambar 2. Activity Diagram Teknisi Monitoring Software 


\section{Activity Diagram Admin}

Activity Diagram Admin merupakan urutan langkah-langkah yang dilakukan Teknisi dalam melakukan tugasnya. Mulai dari menjalankan perangkat lunak, monitoring data trafik kendaraan, sinkronisasi data, export data kendaraan, dan melihat Live Cam atau Snapshoot. Activity Diagram Admin. Gambar 3 pada halaman berikut adalah Activity Diagram Admin dari perangkat lunak Monitoring yang akan dibuat:

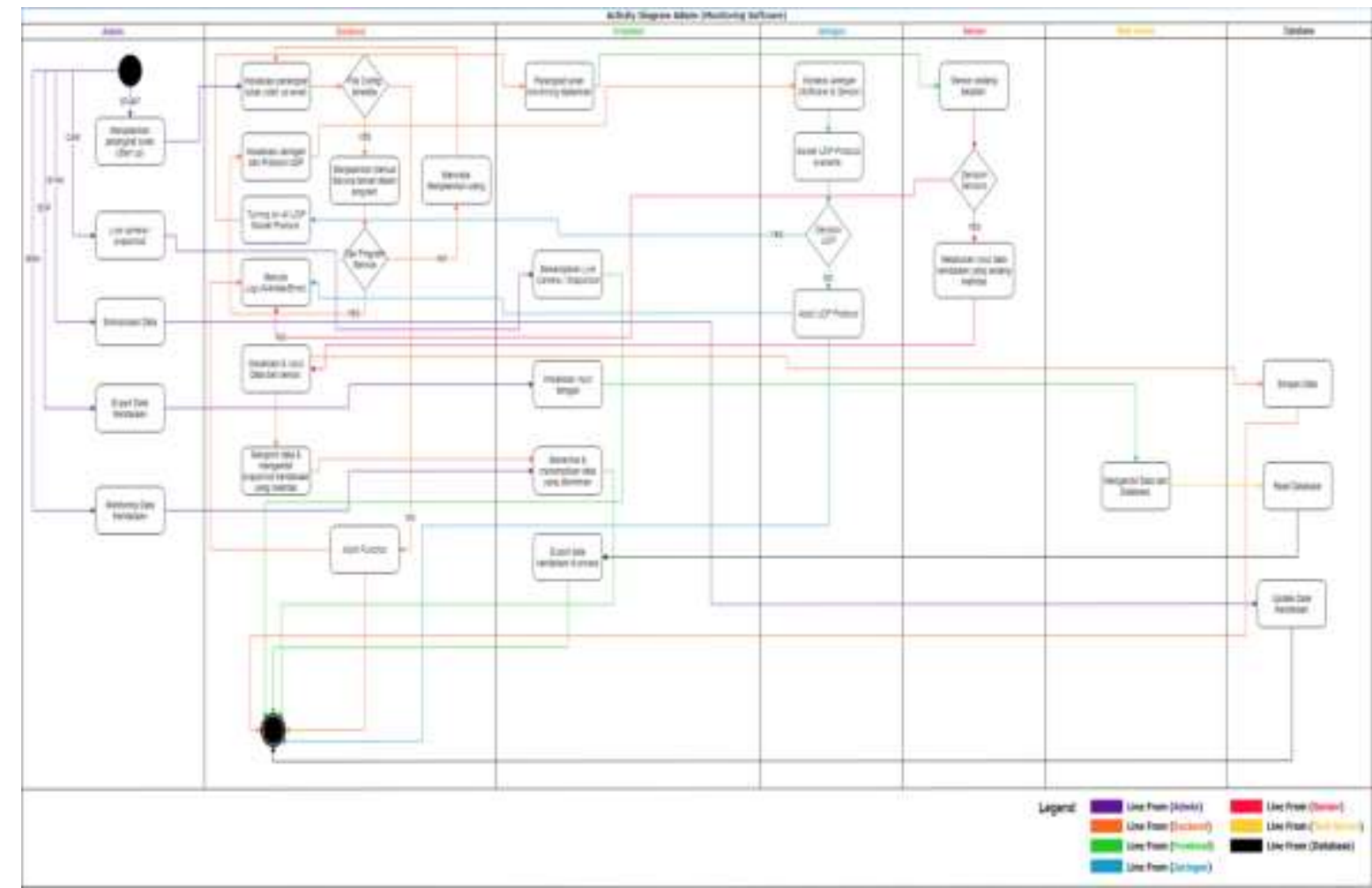

Gambar 3. Activity Diagram Admin Monitoring Software

\section{HASIL PEMBAHASAN}

\subsection{Hasil Penelitian}

Hasil Penelitian ini dijelaskan mengenai Hasil dan Implementasi progam dari berbagai tahapan yang telah dirancang sebelumnya. Perlu diperhatikan sebelum Admin mulai menjalankan perangkat lunak untuk melakukan monitoring, pastikan perangkat (personal computer) memiliki sistem operasi Windows 10 Pro, dan terknoneksi dengan jaringan, dan juga perangkat lunak Backend telah di konfigurasi oleh seorang Teknisi. Setelah poin-poin yang disebutkan sudah tidak ada masalah, maka seorang Admin dapat menjalankan perangkat lunak monitoring tersebut.

\subsubsection{Perangkat Lunak Backend}

Perangkat lunak Backend dalam penelitian ini berbentuk Windows Service yang berjalan di sistem operasi Windows 10 Pro. Gambar 4 berikut ini merupakan perangkat lunak backend atau bisa disebut sebagai otak dari perangkat lunak front end. 


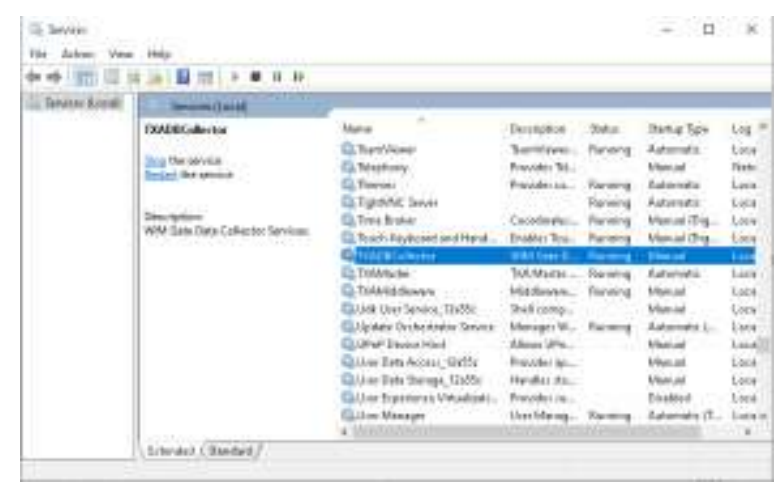

Gambar 4. Perangkat Lunak Backend

\subsubsection{Tampilan Frontend Utama}

Tampilan utama merupakan yang akan selalu dilihat oleh Admin ketika perangkat lunak monitoring telah dijalankan dan sedang bekerja. Gambar 5. berikut ini merupakan Tampilan Utama perangkat lunak monitoring:

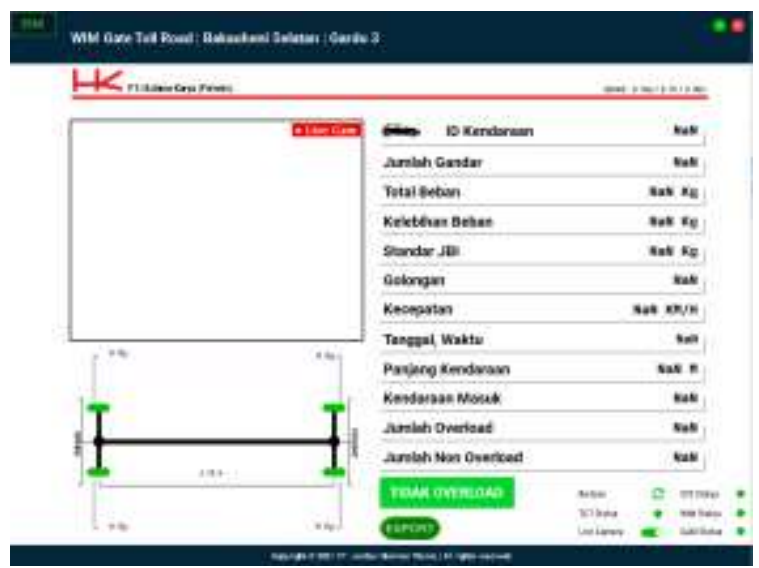

Gambar 5. Tampilan Frontend Utama Monitoring

\subsection{Pembahasan}

Proses pengujian merupakan tahap akhir dimana sistem akan diuji kemampuan dan keefektifannya. Pengujian Perangkat lunak dilakukan dengan menggunakan metode Black-Box Testing, yang merupakan salah satu cara pengujian perangkat lunak yang mengutamakan pengujian terhadap fungsi dari suatu program dan melibatkan pengguna sebagai alat ukur sebuah perangkat lunak. Dalam tahap pengujian perangkat lunak ini dilakakukan pada perangkat yang terdapat program monitoring dan sudah terkonfigurasi.

\section{KESIMPULAN}

\subsection{Kesimpulan}

Berdasarkan hasil pembahasan, maka dapat disimpulkan bahwa Penulis telah berhasil membangun perangkat lunak "Rancang Bangun Perangkat Lunak Monitoring Menggunakan Sensor Timbangan Dinamis Terhadap Muatan Kendaraan dan Penindakan Pada Gerbang Tol" sebuah perangkat lunak yang dapat melakukan proses monitoring data kendaraan secara realtime. Perangkat lunak dibangun menggunakan IDE Microsoft Visual Studio 2019 dengan 
bahasa pemrograman Backend maupun Frontend yang digunakan adalah C\# (C Sharp), dan MySQL sebagai DBMSnya serta menggunakan metode pengembangan perangkat lunak Prototype. Perangkat lunak yang dibangun dapat melakukan monitoring terhadap kendaraan yang melintas dan tentunya masih banyak kendaraan dengan muatan berlebih untuk dilakukan penindakan pada kendaraan dengan muatan berlebih (Overload) yang sering membuat jalan rusak, sehingga pengelola jalan tol terlalu sering melakukan perbaikan jalan dengan cost yang tidak sedikit.

\subsection{Saran}

Saran yang dapat diberikan sebagai perbaikan untuk penelitian yang lebih lanjut adalah sebagai berikut:

1. Penelitian selanjutnya dapat menemukan penyebab error yang belum diketahui sehingga dapat melakukan perbaikan - perbaikan di beberapa error yang terkadang masih terjadi, sehingga perangkat lunak dapat berjalan secara full automatic.

2. Optimalisasi Synchronizing Data agar dapat selalu sesuai dengan penulisan Marking pada gambar kendaraan (Snapshoot) sehingga mencapai 0 persen tingkat error dalam penulisan data.

3. Diharapkan penelitian selanjutnya dapat menerapkan perangkat lunak ini dengan DBMS NoSQL atau melakukan optimasi database agar lebih cepat dalam melakukan pemrosesan data.

\section{DAFTAR PUSTAKA}

Al-Bahra Bin Ladjamudin., 2005, Analisis dan Desain Sistem Informasi, Graha Ilmu, Yogyakarta

Al-Bahra Bin Ladjamudin., 2006, Rekayasa Perangkat Lunak, Graha Ilmu, Yogyakarta

Fakhrudin, Arif., 2020. Aplikasi Desktop Aplikasi Desktop (javatekno.co.id) dikutip pada 4 Juni 2020

I Putu Agus Eka Pratama, S.T., M.T., 20018. Handbook of Datawarehouse, Practice \& Tourism base on Open Source, Informatika.

Handoyo, E. D., \& Risal, L., 2011. Pemrograman Berorientasi Objek C\#. Bandung: Penerbit Informatika.

Munawar., 2018. Analisis Perancangan Sistem Berorientasi Objek dengan Unified Modeling Language (UML). Depok: Informatika.

Roger S. Pressman., 2012. Buku 1 Rekayasa Perangkat Lunak Pendekatan Praktisi Edisi 7. Buku Rekayasa Perangkat Lunak Edisi 7 halaman 50 Tentang Metode Prototype.

Rama, Girish Maskeri dan Avinash Kak., 2013. Software - Practice and Experience. New Jersey: Wiley Online Library.

Rahman, F. and Santoso., 2015. Aplikasi Pemesanan Undangan Online, Jurnal Sanis dan Informatika, 1(2), pp. 7887. 